\section{Using Microsatellites for Paternity Testing in Olive Progenies}

\author{
Raul de la Rosa ${ }^{1}$, Celia M. James, and Kenneth R. Tobutt \\ Horticulture Research International, East Malling, West Malling, Kent ME19, \\ 6BJ, United Kingdom
}

Additional index words. breeding, outcrossing, selfing, incompatibility, Olea europaea

\begin{abstract}
Eight microsatellite primers were used to distinguish 23 olive cultivars that were parents, or potential parents, in a Spanish breeding program. Four of these microsatellites were particularly informative and were used to check the paternity of $\mathbf{1 1}$ olive progenies thought to come from selfings or controlled crosses involving nonemasculated flowers. Seven progenies were found to be highly contaminated, i.e. many seedlings had unexpected alleles, and only four were found to be pure or almost pure. Almost all the contamination detected came from outcrossing, indicating that placing the pollination bags well before anthesis is important and that emasculation to avoid selfing is unnecessary. More than two nonparental alleles per primer were found in each contaminated progeny, showing that more than one cultivar caused contamination. However, the allele data are consistent with 'Picual' (the main commercial cultivar growing in the area where the crosses were made) being the contaminant in $48 \%$ of the nontrue seedlings (excluding 'Picual' self progenies). Some other cultivars planted near the female trees were also found to be sources of contamination. The results obtained show that microsatellite analysis is a convenient technique to assess routinely the crosses made in breeding programs and to check self-incompatibility in olive. The pure progenies identified will be useful for reliable inheritance studies in olive, which have rarely been reported in the literature.
\end{abstract}

Olive (Olea europaea L.), a wind pollinated tree species with small pollen grains (Pacini and Juniper, 1979), has long been economically important around the Mediterranean. Attempts to develop new cultivars in olive have been sporadic (Arsel and Cirik, 1994; Bellini, 1992; Fontanazza and Baldoni, 1990; Lavee, 1989) Among the few olive cultivars obtained by systematic breeding, are 'Kadesh' and 'Barnea' in Israel (Lavee, 1978; Lavee et al., 1986) and 'Fs-17' in Italy (Fontanazza et al., 1998), and these are not widely planted. In a new olive breeding program in Córdoba, Spain aimed at superseding the widely planted cultivar 'Picual' (Rallo, 1995), difficulties have been experienced in developing a good crossing system. It is noteworthy that in both Israel and Spain, a predominant number of seedlings with phenotypic similarities to the female rather than the male parent have been reported (Lavee 1989; León-Moreno, 2002). This low contribution of the nominal male parent to the progenies could indicate some contamination by outcrossing or selfing.

Also, the extent of self-incompatibility in olive is debatable. In Italy, many cultivars are considered self-incompatible (Moretini et al., 1972; Antognozzi and Standardi, 1978). However, in Spain, in a survey of a cultivar collection, a third of the cultivars were reported to be at least partially self-compatible (Cuevas, 1992). Anyhow, the degree of self-incompat-

Received for publication 29 Aug. 2003. Accepted for publication 10 Oct. 2003

${ }^{1}$ To whom reprint requests should be sent. Current address: Olivicultura y Arboricultura Frutal, CIFAAlameda del Obispo, Córdoba (Junta de Andalucia), Avda Menéndez Pidal s/n Córdoba, 14080, Spain. E-mail address: raul.rosa@juntadeandalucia.es ibility has been very variable within cultivars, when studied over several years (Lavee et al., 2002). In those cases, self-incompatibility has been measured by bagging branches just before anthesis and counting the subsequent fruit set.

Molecular markers now offer the means of both genotyping seedlings clearly and confirming their parentage. Microsatellites, which are codominant and particularly polymorphic, are convenient for these purposes, as has been reported in bur oak, another wind pollinated tree (Dow and Ashley, 1998), and in potato (Buetler et al., 2002). Olive microsatellite primers have recently been developed (Rallo et al., 2000; Sefc et al., 2000; Carriero et al., 2002; Cipriani et al., 2002; De la Rosa et al., 2002) for fingerprinting cultivars that can be difficult to distinguish vegetatively. They could also be useful to investigate the occurrence of contamination in olive progenies as well as to check the incompatibility of the olive cultivars.

In this work, the capacity of several microsatellite markers to reveal polymorphism in a set of cultivars involved in the olive breeding program in Córdoba and, subsequently, to check the parentage of progenies raised in it, is evaluated. As a result of this, recommendations are made for overcoming contamination by outcrossing and some conclusions are drawn about the self-compatibility of some olive cultivars.

\section{Materials and Methods}

Plant material and DNA isolation. Initially, a set of 23 cultivars (Table 1) from the World Olive Germplasm Bank of Córdoba (CIFA "Alameda del Obispo", Junta de Andalucía) were used, to establish the ability of the microsatellite primers to distinguish olive cultivars and to select the primers with the best characteristics for use in the paternity tests. This set of cultivars included the five nominal parents of the progenies under study ('Arbequina', 'Lechín de Sevilla', 'Meski', 'Picual', and 'Zaity') and 18 additional cultivars considered potential sources of contamination due to their proximity to some of the parent trees.

The 11 olive progenies used for paternity testing came from crosses of the breeding program of the Univ. of Córdoba (Table 2). They had been made in various years, by different people and at two locations, as follows. Pollen was collected in brown paper bags attached to branches, of trees used as male parents, just before anthesis. Branches of trees used as female parents were covered with tightly attached double perforated plastic bags (Del Río and Caballero, 1999), just before the flowers opened. When the first flowers of the female branches were open, the pollen previously collected was applied to the isolating bags. As there is a considerable overlapping in the flowering period of the cultivars used as parents (Barranco et al., 1994) and the flowering period lasts over $10 \mathrm{~d}$, it was possible to select maternal branches flowering later than paternal ones. In the case of selfing, no extra maternal pollen was introduced into the isolation bags. All the experiments were carried out in research plantings several hundred metres from commercial plantings.

Initially, 20 seedlings from four progenies raised in 1999 were tested for paternity. On the basis of those results (the progenies were totally pure or highly contaminated, but not intermediate), just 10 seedlings were considered sufficient to assess the purity of the remaining seven progenies.

Total DNA from young leaves of these individuals was extracted as described by Murray and Thompson (1980) with the modifications described in De la Rosa et al. (2002).

Microsatellite amplification in cultivar survey and progeny testing. Eight microsatellite primer pairs were tested on the set of 23 cultivars. Six of them (EMO2, EMO3, EMO13, EMO30, EMO88, and EMO90) had been developed by De la Rosa et al. (2002). Two more (DCA9 and DCA18) were selected from the 15 published by Sefc et al. (2000) as they revealed high numbers of alleles and high heterozygosity.

On the basis of the data obtained in the 23 cultivars for these eight microsatellites, four, EMO2, EMO3, DCA9 and DCA18, were selected to test the paternity of the seedlings. In the case of the progenies 'Zaity' $x$ 'Arbequina' and 'Arbequina' $x$ 'Zaity', the primer pair EMO2 was substituted by EMO90 which revealed alleles in the parental cultivars that were rare in the cultivars considered as possible contaminants (Table 1).

Polymerase chain reactions were carried out in $12.5-\mu \mathrm{L}$ volume with the composition and conditions described in De la Rosa et al. (2002). The electrophoreses were performed in an automated sequencer (Perkin-Elmer Applied Biosystems 3100) running Genes- 
Breeding, Cultivars, Rootstocks, \& Germplasm Resources

Table 1. Allele combinations obtained at the eight microsatellite loci in the 23 cultivars. The number of different allele combinations observed and the number of cultivars distinguished by each primer pair is indicated

\begin{tabular}{|c|c|c|c|c|c|c|c|c|}
\hline Cultivar & EMO2 & EMO3 & EMO13 & EMO30 & EMO88 & EMO90 & DCA9 & DCA18 \\
\hline Arbequina $^{z}$ & $210 / 220$ & $211 / 211$ & $120 / 122$ & $180 / 185$ & $185 / 189$ & $183 / 189$ & $182 / 203$ & $165 / 175$ \\
\hline Amigdalolia Nana & $201 / 225$ & $209 / 212$ & $137 / 137$ & $187 / 189$ & $185 / 197$ & $183 / 189$ & $160 / 170$ & $175 / 181$ \\
\hline Arbosana & $220 / 243$ & $207 / 211$ & $122 / 122$ & $185 / 196$ & $183 / 185$ & $180 / 183$ & $192 / 203$ & $165 / 173$ \\
\hline Carolea & $225 / 225$ & $209 / 211$ & $137 / 137$ & $187 / 187$ & $178 / 183$ & $183 / 193$ & $160 / 160$ & $175 / 177$ \\
\hline Cornicabra & $201 / 220$ & $207 / 215$ & $137 / 137$ & $187 / 187$ & $183 / 185$ & $183 / 183$ & $192 / 203$ & $169 / 173$ \\
\hline Domat & $225 / 243$ & $207 / 211$ & $137 / 137$ & $185 / 187$ & $178 / 181$ & $180 / 183$ & $160 / 192$ & $175 / 173$ \\
\hline Empeltre & $220 / 243$ & $205 / 209$ & $122 / 137$ & $187 / 189$ & $183 / 185$ & $189 / 193$ & $184 / 203$ & $167 / 177$ \\
\hline Frantoio & $205 / 220$ & $212 / 212$ & $120 / 137$ & $189 / 189$ & $183 / 183$ & $183 / 189$ & $180 / 207$ & $173 / 175$ \\
\hline Galega & $201 / 210$ & $205 / 207$ & $137 / 137$ & $189 / 192$ & $178 / 185$ & $183 / 183$ & $190 / 192$ & $169 / 177$ \\
\hline Gordal Sevillana & $201 / 201$ & $207 / 209$ & $120 / 120$ & $187 / 189$ & $183 / 183$ & $183 / 183$ & $160 / 192$ & $173 / 177$ \\
\hline Hojiblanca & $201 / 220$ & $207 / 211$ & $122 / 124$ & $185 / 187$ & $185 / 185$ & $183 / 185$ & $192 / 203$ & $169 / 177$ \\
\hline Lechin de Sevilla ${ }^{z}$ & $220 / 227$ & $207 / 211$ & $120 / 137$ & $185 / 187$ & $178 / 178$ & $183 / 183$ & $160 / 203$ & $165 / 173$ \\
\hline Memecik & $201 / 243$ & $207 / 212$ & $137 / 137$ & $187 / 187$ & $185 / 185$ & $183 / 185$ & $192 / 192$ & $167 / 173$ \\
\hline Manzanilla Huercal-Overa & $201 / 211$ & $211 / 215$ & $122 / 122$ & $189 / 192$ & $185 / 189$ & $180 / 183$ & $170 / 178$ & $167 / 169$ \\
\hline Meski $^{\mathrm{z}}$ & $201 / 243$ & $207 / 211$ & $120 / 120$ & $189 / 189$ & $197 / 197$ & $181 / 183$ & $184 / 192$ & $173 / 173$ \\
\hline Manzanilla de Sevilla & $220 / 220$ & $207 / 211$ & $120 / 124$ & $189 / 189$ & $183 / 183$ & $183 / 185$ & $160 / 203$ & $169 / 177$ \\
\hline Nabali & $201 / 210$ & $209 / 211$ & $122 / 124$ & $185 / 189$ & $185 / 185$ & $183 / 183$ & $182 / 192$ & $169 / 173$ \\
\hline Ouslati & $211 / 241$ & $211 / 212$ & $120 / 120$ & $185 / 189$ & $195 / 197$ & $183 / 185$ & $174 / 192$ & $171 / 171$ \\
\hline Picual $^{z}$ & $201 / 210$ & $207 / 215$ & $118 / 137$ & $185 / 187$ & $185 / 185$ & $183 / 183$ & $182 / 190$ & $167 / 173$ \\
\hline Redondilla De Logroño & $201 / 201$ & $209 / 211$ & $137 / 137$ & $185 / 187$ & $183 / 185$ & $183 / 185$ & $170 / 192$ & $175 / 175$ \\
\hline Sevillenca & $205 / 227$ & $207 / 211$ & $137 / 139$ & $189 / 192$ & $183 / 183$ & $183 / 183$ & $160 / 180$ & $171 / 173$ \\
\hline Torcio de Cabra & $243 / 243$ & $207 / 211$ & $120 / 120$ & $183 / 192$ & $178 / 185$ & $185 / 193$ & $184 / 184$ & $167 / 177$ \\
\hline Zaity $^{z}$ & $201 / 201$ & $209 / 210$ & $120 / 120$ & $187 / 187$ & $178 / 185$ & $181 / 197$ & $186 / 192$ & $171 / 179$ \\
\hline No. of different allele combinations & 16 & 13 & 10 & 10 & 11 & 9 & 19 & 17 \\
\hline No. of cultivars distinguished & 11 & 10 & 4 & 4 & 6 & 5 & 16 & 12 \\
\hline
\end{tabular}

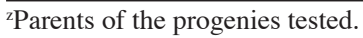

can software and the peaks were checked by eye to detect possible errors in the assignment of alleles.

Data analysis. The peaks present in the 23 cultivars were recorded for each of the eight primer pairs used. These were considered to represent alleles and were referred to by their size in base pairs (given by the Genescan software) rounded to the approximate unit. The number of different genotypes and number of cultivars distinguished by each primer pair were counted. The minimum number of primer pairs sufficient for distinguishing all the cultivars was determined.

For the four primer pairs used in the paternity analysis, the alleles were scored for each seedling. If a seedling presented neither of the two maternal alleles for any of the four primers, it was considered mislabelled. If only maternal alleles were present, the seedling was considered the product of self fertilization. When a nonparental allele was recorded, together with a maternal allele, the seedling was considered to be the product of contamination by outcrossing (outcross seedling). Finally, if one maternal and one paternal allele were present for each primer, the seedling was considered "true".

The frequencies of the maternal and paternal alleles in the progeny 'Picual' $\times$ 'Arbequina', with 20 'true' seedlings, were recorded and the fit to Mendelian ratio $\left(\chi^{2}\right)$ calculated. In the contaminated progenies, the number of non-parental alleles was recorded as well as their frequency in each progeny. The genotypes of the outcross seedlings were compared with the various cultivars analyzed to indicate the possible origin of contaminant genotypes.

\section{Results}

Cultivar identification. The alleles revealed for each cultivar with the eight primer pairs used are shown in Table 1. The number of different allele combinations observed with each primer pair ranged from 9 (EMO90) to 19 (DCA9) and the number of cultivars distinguished ranged from 4 (EMO13 and EMO30) to 16 (DCA9). Of the 28 possible combinations of two microsatellite loci (from the eight scored), 10 were able to distinguish all 23 cultivars; all combinations of three loci distinguished all the cultivars. The set of eight primer pairs revealed at least 6 distinguishing alleles for any two cultivars, with an average of 11.9 and a maximum of 16 . Information on the heterozygosity of the microsatellite loci and number of alleles amplified is given in De la Rosa et al. (2002) for the EMO primers and in Sefc et al. (2000) for the DCA primers, but these were calculated from a different set of cultivars.

Primer pairs EMO2, EMO3, DCA9, and DCA18, which detected high numbers of alleles, revealed a large number of genotypes and distinguished many cultivars (Table 1). For that reason, those four primer pairs were selected for paternity testing.

Paternity testing. With the exception of one mislabelled individual (not having any of the maternal alleles for two of the four primers used) in 'Zaity' $x$ 'Arbequina' '99, the rest of the 149 seedlings analyzed with the four primer pairs mentioned before, showed at least one allele from the maternal parent for each primer. The four nominally self progenies analyzed showed only 3 out of $60(5 \%)$ truly self seedlings (Table 2). The four crosses that include 'Picual' as a male or female parent showed 49 true seedlings out of 50 analyzed $(98 \%)$, but progenies of the other three crosses showed the presence of nonpaternal alleles with only one true seedling out of $39(2 \%)$. Only one nontrue seedling from likely selfing was recorded, in the progeny 'Arbequina' x 'Meski'; the remaining nontrue seedlings were from outcrossing (outcross seedlings).

From the 149 seedlings from the self- and cross-pollination evaluated, a total of 96 seedlings of paternity different from the nominal one (Table 2) were found. Considering all four microsatellites, 36 outcross seedlings had four non-parental bands (one per microsatellite locus), 32 had three, 24 had two and only 4 were identified as nontrue seedlings on the basis of just one nonparental band. The main sources of contamination seem to be 'Picual', 'Lechín de Sevilla', and 'Arbequina'. The allele data is consistent with these cultivars being the male parents of 31 (32\%), $9(9 \%)$, and 9 $(9 \%)$ of the outcross seedlings respectively. Furthermore, the percentage of seedlings with 'Picual' as a contaminant rises to $48 \%$ if the two progenies produced by the nominal selfing of this cultivar are excluded. In two progenies, 'Zaity' x 'Arbequina' '99 and 'Arbequina' $x$ self ' 99 , some other outcross seedlings were apparent (Table 2), the genotypes of which are consistent with outcrossing with the cultivars surrounding the female parent.

In the only progeny with 20 "true" seedlings ('Picual' $x$ 'Arbequina' Córdoba'99), the segregation data were consistent with Mendelian ratio in all four primer pairs tested. For example, for primer EMO2 the frequency of the male alleles $(210$ and 220$)$ were $9: 11\left[P\left(\chi^{2}\right.\right.$ fit to $1: 1)=0.655]$.

\section{Discussion}

The polymorphism generated by the microsatellite primers used here has proved convenient for distinguishing the set of cultivars tested as has been previously stated for other microsatellites developed (Rallo et al., 2000; Cipriani et al., 2002). This has a practical use, for example for determining trueness-to-type 
Table 2. Paternity of the seedlings analysed. The progenies are identified by the nominal parents and the location, Córdoba (C) or Jaén (J), and year of the cross. For each primer, the number of seedlings consistent with paternal alleles (T) and the number of nonpaternal alleles detected in each progeny (NP) is indicated. For the overall primer data, the number of 'true' seedlings and the number of seedlings with parentage consistent with other cultivars is indicated.

\begin{tabular}{|c|c|c|c|c|c|c|c|c|c|c|c|c|}
\hline \multirow[b]{3}{*}{ Progeny } & \multirow{2}{*}{\multicolumn{2}{|c|}{ EMO2 }} & \multirow{2}{*}{\multicolumn{2}{|c|}{ EMO3 }} & \multirow{2}{*}{\multicolumn{2}{|c|}{ EMO90 }} & \multirow{2}{*}{\multicolumn{2}{|c|}{ DCA9 }} & \multirow{2}{*}{\multicolumn{2}{|c|}{ DCA18 }} & \multicolumn{2}{|r|}{ Overall primer data } \\
\hline & & & & & & & & & & & \multirow{2}{*}{$\begin{array}{c}\text { True seedlings } \\
\text { total }\end{array}$} & \multirow{2}{*}{$\begin{array}{l}\text { Possible other parent } \\
\text { (no. of seedlings) }\end{array}$} \\
\hline & $\mathrm{T}^{\mathrm{z}}$ & $\mathrm{NP}^{\mathrm{z}}$ & $\mathrm{T}$ & NP & $\mathrm{T}$ & NP & $\mathrm{T}$ & $\mathrm{NP}$ & & NP & & \\
\hline Arbequina X self C'99 & 8 & 2 & 4 & 5 & $\begin{array}{ll}-- \\
-1\end{array}$ & $\begin{array}{ll}-- \\
-1\end{array}$ & 4 & 4 & 4 & 6 & $2 / 20$ & Picual (7), Ouslati (4), Galega (1) \\
\hline Lechin de Sevill' $x$ self C'98 & 2 & 2 & 6 & 1 & --- & --- & 2 & 2 & 5 & 2 & $0 / 10$ & Picual (8) \\
\hline Picual $x$ self J'93 & 6 & 2 & 2 & 1 & --- & --- & 2 & 3 & 2 & 2 & $1 / 10$ & Arbequina (7) \\
\hline Picual x self C'99 & 3 & 3 & 10 & 2 & --- & --- & 1 & 4 & 4 & 4 & $0 / 20$ & Lechín de Sevilla (9) \\
\hline Total self progenies & 19 & 9 & 22 & 9 & --- & --- & 9 & 13 & 15 & 14 & $3 / 60$ & \\
\hline Arbequina x Meski C'98 & 2 & 3 & 5 & 1 & --- & --- & 1 & 4 & 3 & 4 & $0 / 10$ & Picual (7), Arbequina (1) \\
\hline Arbequina $x$ Picual J'93 & 10 & 0 & 10 & 0 & --- & --- & 10 & 0 & 10 & 0 & $10 / 10$ & \\
\hline Arbequina x Zaity C'98 & --- & --- & 0 & 3 & 0 & 2 & 0 & 3 & 0 & 3 & $0 / 10$ & Picual (9) \\
\hline Picual $\times$ Arbequina J'93 & 10 & 0 & 10 & 0 & --- & --- & 10 & 0 & 10 & 0 & $10 / 10$ & \\
\hline Picual x Arbequina C'99 & 20 & 0 & 20 & 0 & --- & --- & 20 & 0 & 20 & 0 & $20 / 20$ & \\
\hline Picual x Lechín de Sevilla C'98 & 10 & 0 & 9 & 1 & --- & --- & 9 & 1 & 9 & 1 & $9 / 10$ & Arbequina (1) \\
\hline Zaity x Arbequina C'99 & --- & --- & 5 & 6 & 2 & 3 & 5 & 4 & 5 & 5 & $1 / 19^{y}$ & Redondilla de Logroño (3), Cornicabra (2) \\
\hline Total cross progenies & 52 & 3 & 59 & 11 & 2 & 5 & 55 & 12 & 57 & 13 & $50 / 89$ & \\
\hline
\end{tabular}

${ }^{2}$ True seedlings and no. of nonpaternal alleles, identified per primer, are calculated over the total number of seedlings evaluated per progeny.

${ }^{\mathrm{y}}$ One mislabelled seedling not considered.

of vegetative material in the nursery. In fact, some of the cultivars included here, 'Arbequina', 'Empeltre', 'Frantoio', 'Manzanilla de Sevilla', and 'Picual', are widely used by growers in several Mediterranean countries. Additionally, the allelic data obtained in this study could be used by other research workers to check the identity of the cultivars presented here with cultivars of the same name in other locations. This is possible because microsatellites should be "transferable" between laboratories (Jones et al., 1997).

In addition, the consistency, polymorphism and codominance of the microsatellites in olive (Rallo et al., 2000; Sefc et al., 2000; Carriero et al., 2002; De la Rosa et al., 2002) make them good tools for assessing the purity of olive progenies. With just four primer pairs, selected from the eight used for cultivar identification, we were able to distinguish severely contaminated progenies from apparently pure, or almost pure progenies. In fact, 92 out of the 96 outcross seedlings detected were identified on the basis of two or more nonparental bands.

The allele data for almost half of the outcross seedlings (excluding the 'Picual' self progenies) are consistent with 'Picual' being the contaminant. This suggests that much of the airborne pollen came from this cultivar, the main commercial cultivar in Córdoba and Jaén, where the pollinations were performed. This indicates that pollen can travel over several hundred metres in olive, as has been detected in bur oak, also with a set of four microsatellites (Dow and Ashley, 1998).

The only progeny not showing 'Picual' contamination, 'Zaity' $x$ 'Arbequina', is the one made in the middle of the germplasm bank of Córdoba where, presumably, the composition of the airborne pollen was different. In fact, some of the contaminants identified in this progeny are cultivars planted next to the mother tree. Another possibility is that 'Zaity' and 'Picual' are cross-incompatible, but specific experiments would be needed to clarify this. The rest of the crosses were made in trees in a trial plantation with, among other cultivars, Picual,Lechín de Sevilla, Arbequina,
Ouslati, and Galega, which have been detected as likely sources of pollen. In any case, the presence of more than two illegitimate alleles among the outcross seedlings of each progeny demonstrates that there is not just one genotype causing contamination. In most cases, the alleles of the nominal male parent (data not shown) are relatively infrequent in the outcross seedlings, showing the power of each primer pair to detect contamination. In particular, the primer pair EMO90, used for 'Zaity' $x$ 'Arbequina', shows only one (supposedly) paternal allele (183) in the 19 outcross seedlings.

All the progenies considered pure (or almost pure) have 'Picual' as a parent (three as female and one as male parent). This could explain why they are not so severely contaminated since it has been reported that foreign pollen competes favorably with maternal pollen in pollination (Cuevas et al., 1994). Therefore, the airborne pollen, mainly 'Picual' as mentioned before, would not have competed with the crossing pollen in the progenies with 'Picual' as female parent and, consequently, the possibility of contamination would be lower. When 'Picual' was the male parent, the crosses were also pure, maybe because both the male and airborne pollen came from the same cultivar. This, together with the fact that only one of the 30 seedlings evaluated from the supposed selfing of 'Picual', seems to be a genuine self, indicates that 'Picual' could be self-incompatible. However, more experimentation is needed to clarify this point.

The possibilities of contamination in olive crosses, inferred from previous Israeli and Spanish agronomic data showing skewed segregation in agronomic traits in olive progenies (Lavee 1989; León-Moreno, 2002), have been demonstrated in these paternity studies of Spanish progenies. Interestingly, although emasculation is not practised in olive crossing at Córdoba, contamination by selfing seems not to be a problem in any of the progenies analyzed here, made by different people in different years and locations. In fact, only one seedling of the seven progenies from crossing seems to have originated from selfing. On the contrary, most of the contamination comes from pollen of other cultivars. Presumably, airborne pollen entered the crossing bags when they were being attached to the branch of the female trees just before their anthesis. This is possible since there is a considerable overlapping of the flowering periods of different olive cultivars (Barranco el al., 1994). As the male pollen is introduced only when some female flowers are open, some of the airborne pollen already in the bags could have pollinated these early opened flowers. In olive, the competition among fruits is very strong and only the first fruits set will survive. This interpretation is supported by the fact that, even though no pollen was introduced into the selfing bags, the corresponding progenies were still contaminated. Another possibility is that the pollination bags used were not really pollen-proof, despite previous reports (Del Rio and Caballero, 1999). In this case, airborne pollen could have entered after the bag was placed causing contamination. In the cross progenies, the contamination could also occur in the collection of the male pollen, but then the proportion of contaminant pollen with respect to the true-male pollen would be very low and, therefore, the contamination from this source is unlikely to be as great as revealed by the microsatellite data. Mislabelling of the seeds is unlikely to have occurred since alleles not corresponding to any of the cultivars used as parents, were found in the contaminated progenies. Also because, for each locus, virtually all the seedlings have an allele in common with the nominal mother.

On the basis of the data obtained here, it is possible to make important recommendations for olive crossing. Emasculation seems unnecessary, at least for the cultivars used here, since almost no contamination from selfing has been detected. The traditional method to assess contamination by counting the number of fruits in selfing bags (Lavee, 1989), is not able to detect contamination by airborne pollen, which seems to be the main problem here. What appears to be important for the success of the crosses is to place the crossing bags on the female tree, well before 
the anthesis of any cultivar when there is no pollen in the air. The same would be true for incompatibility studies where, traditionally, the pollination bags are also placed just before anthesis of the particular cultivar being studied (Moretini et al., 1972; Antogonozzi and Standardi, 1978; Bartolini and Guerrirero, 1995; Cuevas and Polito, 1997).

The short DNA extraction protocol and the highly polymorphic nature of the microsatellites developed in olive, makes microsatellite analysis a convenient technique for assessing routinely the crosses made in breeding programs, and for confirming cross and self-compatibility. If the main problem of the progenies is outcrossing and not selfing, the best characteristic for primers used for paternity testing is not high polymorphism between the parents, but polymorphism with respect to potential rogue parents. Then, the same set of primers could be used to determine paternity in different progenies.

Apart from the consequences for pollination protocols in olive, the paternity tests developed here have identified several progenies that seem to be pure or almost pure. The screening of the remaining seedlings in these progenies would provide the necessary material to start inheritance analyses in olive for both agronomic traits and molecular markers.

\section{Literature Cited}

Antognozzi, E. and A. Standardi. 1978. Study of the floral biology of the olive cultivars Gentile di Chieti and Dritta di Moscufo. Rivista della Ortoflorofrutticoltura Italiana 61:461-469.

Arsel, H. and N. Cirik. 1994. General overview of olive breeding in Turkey. Olivae, 52, 25-7.

Bartolini, S. and R. Guerriero. 1995. Self-compatibility in several clones of oil olive cv. Leccino. Adv. Hort. Sci. 9:71-74.

Bellini, E. 1992. Behaviour of some genetic characters in olive seedlings obtained by cross-breed- ing. Acta Hort. 317:197-208.

Barranco, D., G. Milona, and L. Rallo. 1994. Épocas de floración de cultivares de olivo en Córdoba. Investigación Agraria: Producción y Protección Vegetal 9:213-220.

Buetler, M.I. and D.R. Labonte. 2002. Microsatellite-based paternity analysis in polyploid sweetpotato. J. Amer. Soc. Hort. Sci. 127:392-396.

Carriero, F., G. Fontanazza, F. Cellini, and G. Giorio. 2002. Identification of simple sequence repeats (SSRs) in olive (Olea europaea L.). Theor. Appl. Genet. 104:301-307.

Cipriani, G., M. Marazzo, R. Marconi, A. Cimato, and R. Testolin. 2002. Microsatellite markers isolated in olive are suitable for individual fingerprinting and reveal polymorphism within ancient cultivars (Olea europaea L). Theor. Appl. Genet. 104:223-228

Cuevas, J. 1992. Incompatibilidad polen-pistilo, procesos genéticos y fructificación en cultivares de olivo (Olea europaea L.). PhD thesis, Univ. of Córdoba, Spain.

Cuevas, J. and V.S. Polito. 1997. Compatibility relationships in 'Manzanillo' olive. HortScience, 32, 1056-1058.

Cuevas, J., H.F. Rapoport, and L. Rallo. 1994. Pollen-pistil incompatibility differences between 'Manzanillo' and 'Frantoio' olive (Olea europaea L). HortScience, 29:541

De la Rosa, R., C.M. James, and K.R. Tobutt. 2002. Isolation and characterisation of polymorphic microsatellites in olive (Olea europaea L.) and their transferability to other genera in the Oleaceae. Mol. Ecol. Notes, 2:265-267.

Del Río, C. and J. Caballero. 1999. A new bag for olive pollination studies. Acta Hort. 474:233-235.

Dow, B.D. and M.V. Ashley. 1998. High levels of gene flow in bur oak revealed by paternity analysis using microsatellites. J. Hered. 89:62-70.

Fontanazza, G. and L. Baldoni. 1990. Proposed program for the genetic improvement of the olive. Olivae 34:32-40.

Fontanazza, G., Bartolozzi F., and G. Vergati. 1998. Fs-17. Rivista di Frutticoltura e di Ortofloricoltura 5:61

Jones, C.J., K.J. Edwards, S. Castaglione, M.O. Winfield, F. Sala, C. Van-de wiel, G. Bredemeijer, B.
Vosman, M. Matthes, A. Daly, R. Brettschneider, P. Bettini, M. Buiatti, E. maestri, A. Malcevschi, N. Marmiroli, R. Aert, G. Volckaert, J. Rueda, R. Linacero, A. Vazquez, and A. Karp. 1997. Reproducibility testing of RAPD, AFLP and SSR markers in plants by a network of European laboratories. Mol. Breed. 3:381-390.

Lavee, S. 1978. 'Kadesh' table olive. HortScience 13:62-63.

Lavee, S. 1989. Aims, methods and advances in breeding of new olive (Olea europaea L.) cultivars. Acta Hort. 286:23-40.

Lavee, S., A. Haskal, and M. Wodner. 1986. 'Barnea': A new olive cultivar from first breeding generation. Olea 17:95-99.

Lavee, S., J. Taryan, J. Levin, and A. Haskal. 2002. Importancia de la polinización cruzada en distintas variedades de olivo cultivadas en olivares intensivos de regadío. Olivae 91:25-36.

León-Moreno, L. 2002. Evaluación agronómica de progenies de olivo (Olea europaea L.) y puesta a punto de la técnica NIRS para su uso en mejora vegetal. PhD Thesis. Univ. of Córdoba, Spain. 176 p.

Morettini, A., G. Bini, and E. Bellini. 1972. The performance of several French and Spanish table olive cultivars in the Maremma district of Tuscany. Rivista della Ortoflorofrutticoltura Italiana 56:3-19.

Murray, M.G. and W.F. Thompson. 1980. Rapid isolation of high molecular weight plant DNA. Nucl. Acid Res. 8:4321-4325.

Pacini, E. and B.E. Juniper. 1979. The ultrastructure of pollen-grain development in the olive (Olea europaea L.): 1 Proteins in the pore. New Phytol. 83:157-163.

Rallo, L. 1995. Selección y mejora genética del olivo en España. Olivae 59:46-53.

Rallo, P., G. Dorado, and A. Martin. 2000. Development of simple sequence repeats (SSRs) in olive tree (Olea europaea L.). Theor. Appl. Genet. 101:984-989.

Sefc, K.M., M.S. Lopes, D. Mendonça, M. Rodrigues dos Santos, M.L. Da Camara Machado, and A. Da Camara Machado. 2000. Identification of microsatellite loci in olive (Olea europaea L.) and their characterisation in Italian and Iberian olive trees. Mol. Ecol. 9:1171-1193. 